\title{
Nicotine-Induced Loss of Cortical Microtubules in Root Tip Cells of Alfalfa (Medicago sativa) ${ }^{1}$
}

\author{
A. P. Singh ${ }^{2}$ \\ Department of Biology, Texas A. \& M. University, \\ College Station, Texas, U.S.A.
}

Received April 24, 1979

Microtubules are considered common cytoplasmic components of eucaryotic cells. Several reviews (Newcomb 1969, Hepler and Palevitz 1974, Pickett-Heaps 1974 ) and the proceedings of a recently held international symposium (see Deysson 1975) on microtubules have provided a comprehensive coverage on the location, structure and function of microtubules and on the sensitivity of microtubules to antimicrotubular agents. Microtubules present in the cortical cytoplasm of young parenchymatous plant cells are considered to play a determining role in the orientation of wall microfibrils during wall growth; support for which comes from the experiments which have employed colchicine, a familiar antimicrotubular drug, in the investigation of relationships between cortical microtubules and wall microfibrils and from numerous published reports which contain electron micrographs demonstrating a close correlation in the orientation of cell wall microfibrils and underlying cortical microtubules.

In our experiments, nicotine-treated root tip cells of alfalfa (Medicago sativa) exhibited a number of ultrastructural peculiarities, most pronounced being the loss of cortical microtubules, disorganization of dictyosomes and a corresponding cessation of wall growth, and an increase in cytoplasmic density, in vacuolation and in the density of mitochondrial stroma. This report focuses on the loss of cortical microtubules in root tip cells subjected to prolonged nicotine treatments.

\section{Materials and methods}

Alfalfa seeds were germinated (four days) on filter paper moistened with distilled water. Seedlings were then placed either in a $300 \mathrm{mg} / \mathrm{l}$ aqueous nicotine solution or in distilled water (control). Root tips upto $2 \mathrm{~mm}$ in length were sampled at $1,4,8,16,24$, and $48 \mathrm{hr}$ from treated and control seedlings and processed for electron microscopy. Root tips were fixed in $3 \%$ glutaraldehyde in $0.05 \mathrm{M}$ sodium cacodylate buffer for $1 \mathrm{hr}$ at room temperature and for the next $14 \mathrm{hr}$ at $4^{\circ} \mathrm{C}$. Subsequently, samples were washed with several changes of the buffer, post-fixed in $2 \%$ osmium tetroxide in $0.05 \mathrm{M}$ sodium cacodylate buffer for $1 \mathrm{hr}$ at room temperature and washed again in the buffer. Dehydration was carried out in a graded series of acetone and samples were embedded in Spurr's low-viscosity resin. Ultrathin

I I thank Dr. D. M. J. Mueller for his helpful comments on the manuscript. Part of this study was carried out at the University of Hawaii - Hilo.

2 Ple ent address: Forest Research Institute, Private Bag. Rotorua, New Zealand. 
sections were sequentially stained for 2 min with $1 \%$ aqueous potassium permanganate and for $7 \mathrm{~min}$ with lead citrate, according to a recently described procedure (Bray and Wagenaar 1978). Stained sections were examined and photographed in a Zeiss $9 \mathrm{~S}-2$ electron microscope.

\section{Observations and discussion}

A survey of nicotine treated root tip sections of alfalfa showed that cortical microtubules were affected by prolonged treatments of nicotine. In 1-16 hr treated

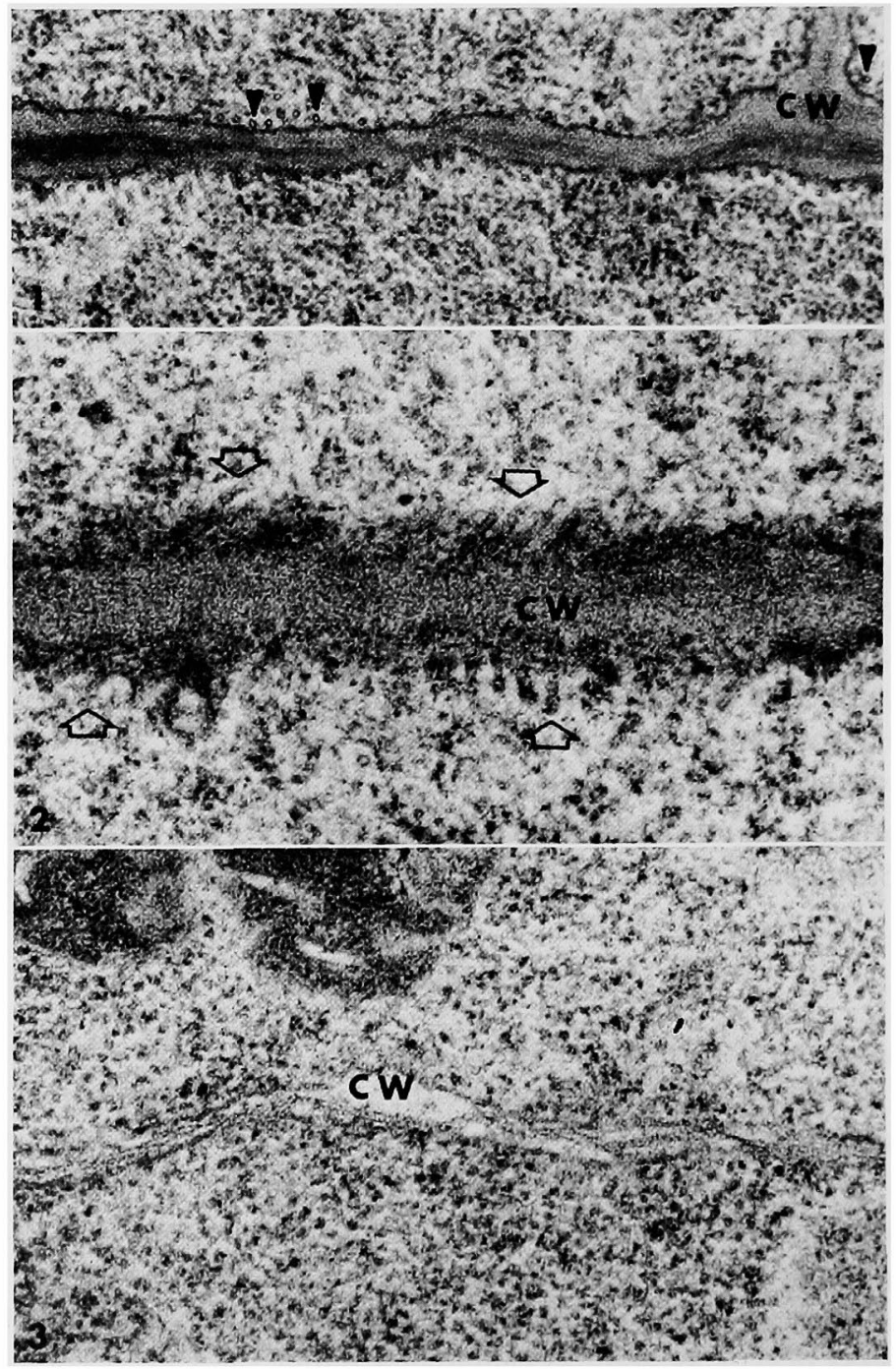

Figs. 1-3. 1 and 2. Parts of two subepidermal cortical cells from $48 \mathrm{~h}$ control material. 1 , cortical microtubules are seen in their circular profile (arrowheads) in this paradermal section. $\times 36,000$. 2, cortical microtubules are exposed along their length (hollow arrows) in this glancing paradermal section. $\mathrm{CW}$, cell wall. $\times 54,000$. 3, paradermal section through parts of two subepidermal cortical cells treated with nicotine for $48 \mathrm{~h}$. Cortical microtubules are absent.

Cytoplasm is dense and wall is extremely thin. CW, cell wall. $\times 54,000$. 
materials cortical microtubules did not appear to suffer a loss in number. Microtubules were present in $24 \mathrm{hr}$ treated material, though in significantly reduced numbers, and were completely lost in $48 \mathrm{hr}$ treated material (Fig. 3). In control materials, cortical microtubules were always found in their usual location underlying the plasmalemma (Figs. 1 and 2).

Nicotine is known to affect a variety of cell components in animal and plant systems (Peirone 1974; Singh, personal observations), but its effect on microtubules was not previously known. The effect of tobacco smoke condensates in inducing abnormal mitosis has been documented in a number of investigations, including those with onion root tip cells. In onion root tip cells, water-soluble extract of tobacco smoke condensate caused irregular mitotic divisions, which included failure of chromosomes to align on the metaphase plate and lagging of chromosomes at anaphase (Bhalla et al. 1973). Since nicotine is regarded as one of the major constituents of tobacco smoke, it is possible that the irregular mitotic divisions observed in onion root tip cells (Bhalla et al. 1973) resulted from the adverse effect of the nicotine fraction of tobacco condensate on spindle microtubules. Efforts are presently underway to test this supposition in alfalfa root tip cells and also to find out if nicotine effects are reversible.

The discovery that nicotine treatment resulted in the loss of cortical microtubules is significant when we consider that: a) the sensitivity of microtubules to nicotine has not hitherto been reported, b) it demonstrates how nicotine may regulate a cell process, and c) it opens up the possibility that nicotine may prove to be a useful research tool in studies of microtubule directed regulatory cell processes.

\section{Summary}

Cortical microtubules disappeared in root tip cells of alfalfa which received prolonged treatments of nicotine at a $300 \mathrm{mg} / \mathrm{l}$ concentration.

\section{References}

Bhalla, P. R., Kochhar, T. S. and Sabharwal, P. S. 1973. Induction of mitotic abnormalities in onion root-tips by tobacco smoke condensate. Cytologia $38: 707-712$.

Bray, D. F. and Wagenaar, E. B. 1978. A double staining technique for improved contrast of thin sections from spurr-embedded tissue. Can. J. Bot. 56: 129-132.

Deysson, G. 1975. Microtubules and antimitotic substances. In Microtubules and Microtubule Inhibitors. Borgers, M., De Brabander, M., eds., Amsterdam: North-Holland Publishing Company.

Hepler, P. K. and Palevitz, B. A. 1974. Microtubules and microfilaments. Annu. Rev. Plant Physiol. 25: 309-362.

Newcomb, E. H. 1969. Plant microtubules. Annu. Rev. Plant Physiol. 20: 253-288.

Peirone, S. 1974. Action of nicotine on chick embryo heart cells cultivated in vitro. J. Submicr. Cytol. 6: 339-352.

Pickett-Heaps, J. D. 1974. Plant microtubules. In Dynamic Aspects of Plant Ultrastructure. Robards, W., ed., London: McGraw-Hill Book Company. 